\title{
A New Serovar and a New Serological Variant Belonging to Salmonella enterica Subspecies diarizonae
}

\author{
CA Solari/ ${ }^{+}$, JR Mandarino, MHM Panizzutti* , RHG Farias* \\ Laboratório de Patologia Clínica, Hospital Universitário Gaffrée e Guinle, Universidade do Rio de Janeiro, Rua Mariz e Barros \\ 775, 20270-004 Rio de Janeiro, RJ, Brasil *Instituto de Biologia do Exército, Rio de Janeiro, RJ, Brasil
}

Description of a new serovar (S. IIIb 16:k:e,n,x,z $\left.{ }_{15}\right)$ and a new serological variant (S. IIIb $\left.42: z_{10}: e, n, x, z_{15}: z_{60}\right)$ belonging to the genus Salmonella isolated from stool specimens of Brazilian snakes (Crotalus durissus).

Key words: Salmonella - new serovar - new serological variant

The genus Salmonella comprises two species: (1) $S$. enterica, which is divided into six subspecies: S. enterica subspecies enterica (I), S. enterica subspecies salamae (II), S. enterica subspecies arizonae (IIIa), S. enterica subspecies diarizonae (IIIb), S. enterica subspecies houtenae (IV) and S. enterica subspecies indica (VI); and (2) S. bongori (formely called $S$. enterica subspecies bongori V). Species and subspecies can be distinguished on the basis of differential characters, and these, through antigenic formulas, into 2,501 serovars. Usually the 1,478 serovars that belong to the enterica species enterica subspecies (I) colonize the enteric tract of warm-blooded animals, while the other 1,023 serovars belonging to subspecies of the II, IIIa, IIIb, IV and VI and to species S. bongori are found in cold-blooded animals and in the environment (Popoff 2001).

Considering the presence of Salmonella in snakes, as previously described (Hinshaw \& McNeil 1945, Zwart 1960, Biggland \& Fox 1967, Mayer \& Frank 1974, Cambre et al. 1980, Onderka \& Finlayson 1985, Ackman et al. 1995, Sá \& Solari 2001), we established a survey for Salmonella organisms in Brazilian snakes maintained at the ofidarium of the Instituto de Biologia do Exército. One previously unknown serovar and one serological variant belonging to Salmonella IIIb were found.

In our methodology, cloacal swabs from snakes ( $\mathrm{Cro}-$ talus durissus) were introduced in Cary-Blair transport medium (Difco) and pre-enriched in $10 \mathrm{ml}$ of Buffered Peptone Water (Merck) incubated $16-18 \mathrm{~h}$ at $37^{\circ} \mathrm{C}$. An aliquot of $0.1 \mathrm{ml}$ was transferred to $10 \mathrm{ml}$ of RappaportVassiliadis (Merck). After incubation at $37^{\circ} \mathrm{C}$ for 18 to 24 $\mathrm{h}$, the broth was streaked onto indicative selective media (Hektoen Enteric Agar, Merck). After incubation at $37^{\circ} \mathrm{C}$ for 18 to $24 \mathrm{~h}$, three to five colonies suspected of Salmo-

$\overline{{ }^{+} \text {Corresponding author. Fax: }}+55-21-2569.4075$. E-mail: solarica@domain.com.br

Received 12 August 2002

Accepted 30 December 2002 nella, were submitted to preliminary biochemical identification using Triple Sugar Iron Agar, Lysine Iron Agar and Urea Broth (Merck). Strains presenting a biochemical profile suggestive of Salmonella were submitted to additional biochemical tests (Ewing 1986). The strains confirmed as Salmonella were differentiated in species and subspecies (Popoff 2001). Both strains were recognized as belonging to $S$. enterica subspecies diarizonae (Table).

Before performing the antigenic characterization (rapid slide agglutination), each culture was tested for smooth (S) or rough phase (R) by inspection of suspensions made done in $2 \%$ saline solution. Once in the smooth phase, the cultures were serotyped by using Salmonella $\mathrm{OH}$ polyvalent antiserum (Fundação Oswaldo Cruz), somatic (O) and flagellar $(\mathrm{H})$ polyvalent antisera and the respective monovalent antisera (Difco and Sanofi-Pasteur) (Popoff 2001). One of the strains (strain no. 4, also de-

TABLE

Biochemical characteristics of a new serovar and a new serological variant of Salmonella enterica subspecies diarizonae identified in the present study

\begin{tabular}{lcc}
\hline Strains & $4^{a}$ & $25^{b}$ \\
\hline Dulcitol $^{a}$ & - & - \\
ONPG $^{c}(2 \mathrm{~h})$ & + & + \\
Malonate $_{\text {Gelatinase }}$ & + & + \\
Sorbitol & + & + \\
Culture with KCN & + & + \\
d-tartrate & - & - \\
Galacturonate & + & - \\
$\gamma$-glutamyltransferase & + & + \\
$\beta$-glucuronidase & + & + \\
Mucate & - & - \\
Salicine & - & - \\
Lactose & - & - \\
Lysis by phage O1 & + & -
\end{tabular}

$a$ : isolated from snake captured in Três Corações, Minas Gerais (Institut Pasteur no. 9173/01); $b$ : isolated from snake captured in Valença, Rio de Janeiro (Institut Pasteur no. 9192/ 01); c: Onitrophenyl ß-galactosidase 
nominated as Institut Pasteur 9173/01), isolated from a snake captured in Três Corações, state of Minas Gerais, presented the antigenic formula $42: \mathrm{z}_{10}:$ e, $\mathrm{n}, \mathrm{x}, \mathrm{z}_{15}: \mathrm{z}_{60}$ (triphasic variant). The other strain (strain no. 25, also denominated as Institut Pasteur no. 9192/01) had the antigenic formula $16: \mathrm{k}: \mathrm{e}, \mathrm{n}, \mathrm{x}, \mathrm{z}_{15}$ (new serovar). The new serovar and the new serological variant of $S$. enterica subspecies diarizonae in the present communication will be included in the next edition (9th) of the KauffmannWhite Scheme.

\section{ACKNOWLEDGEMENTS}

To Dr Michel Y Popoff for the biochemical and serological confirmations of strains. WHO Collaborating Centre for Reference and Research of Salmonella, Institut Pasteur, Paris, France.

\section{REFERENCES}

Ackman DM, Drabkin P, Birkhead G, Cieslak P 1995. Reptile associated salmonellosis in New York State. Pediatr Infect Dis J 14: 955-959.

Biggland CH, Fox G 1967. Salmonella essen and Arizona 12:27-
28 isolations from saskatchewan garter snakes. Can $J$ Microbiol 13: 1049-1050.

Cambre RC, Green DE, Smith EE, Montali RJ, Bush M 1980. Salmonella and arizonosis in the reptile collection at the National Zoological Park. JAVMA 177: 800-803.

Ewing WH 1986. Edwards \& Ewing. Identification of Enterobacteriaceae, 4th ed., Elsevier, New York.

Hinshaw WR, McNeil E 1945. Salmonella types isolated from snakes. Am J Vet Res 6: 264-266.

Mayer H, Frank W 1974. Bacteriological investigations on reptiles and amphibians. Zbl Bakt Hyg I Abt Orig A 229: 470481.

Onderka DK, Finlayson MC 1985. Salmonellae and salmonellosis in captive reptiles. Can J Comp Med 49: 268-270.

Popoff MY 2001. Antigenic Formulas of the Salmonella Serovars, 8th ed., WHO Collaborating Centre for Reference and Research on Salmonella, Institut Pasteur, Paris, France.

Sá IVA, Solari CA 2001. Salmonella in Brazilian and imported pet reptiles. Br J Microbiol 32: 293-297.

Zwart P 1960. Salmonella and Arizona infections. Antonie van Leeuw 26: 250-254. 